\title{
How volunteering for an MRI scan changed my life
}

\author{
Discovering a serious problem not only causes shock but can have financial implications.
}

Sir - I read your news story "Brain-scan ethics come under spotlight" (Nature 433, $185 ; 2005)$ with great interest. As a neuroscientist, and being a bit of a 'neuro-nerd', I've always wanted to observe MRI scans of my own brain, so when the opportunity arose I jumped at the chance to help test a new MRI facility at my university.

As it turns out, I should have thought about the consequences of volunteering more thoroughly.

After the test scans, the manager of the facility informed me that something abnormal had been observed during the procedure. With great trepidation, I looked through the scans and, having taught neuroanatomy previously, I instantly recognised a tumour, roughly the size of a golf ball, in a rather sensitive location near the carotid artery to the left of my brainstem. This came as a huge surprise as I had never been diagnosed with any sort of neurological disorder.

Some would call this a fortunate discovery, and I would normally agree with them. Clearly, knowing you have a brain tumour is better than not knowing, right? The manager of the MRI facility offered to refer me to a local neurosurgeon for further investigation. In a state of shock, I agreed without proper consideration. This decision, I later realized, would have unforeseen financial implications.

At the time, my wife and I were expecting our first child, and we were in the process of reviewing our insurance policies. We had decided to apply for additional insurance to support the family should one of us lose our university position though injury or disease. Just before we submitted these documents, along came this 'diagnosis'.

The neurosurgeon told me that $5 \%$ of operations lead to potential complications after which, in order to save my life, they would have to induce a massive stroke of my entire left-brain. This could leave me in the horrible position of being unable to communicate with my wife, my newborn child or my students. Clearly, this surgery could lead to my losing my job. What should I do about the insurance policy? Revise the application and report these 'non-clinical' scans? I decided to be honest (others would say naive) and report the scans, which cost me the policy.

Now I sit in the uneasy position of facing surgery that could cost me and my family everything because I wanted to peep at my own brain. I understand that subject recruitment for research studies can be very difficult and every subject is precious. After my experience, however, I feel that informed consent should clearly include recognizing the possibility that something of medical significance could arise and that this could have an impact on future insurance eligibility.

Sadly, this is likely to further reduce subject participation in research critical to our understanding of the healthy and diseased brain.

Name and address withheld by request

\section{Coping with unsuspected findings in volunteers}

Sir - I read your News story "Brain-scan ethics come under spotlight" (Nature 433, $185 ; 2005)$ with a feeling of déjà vu.

Nearly 20 years ago, my colleague Alfredo Vazquez and I reported a group of 'normal' volunteers who were discovered to have serious abnormalities during the course of research.

Of the three apparently healthy young medical students concerned, one was found to have chronic persistent hepatitis, another had a tumour in the parietal lobe of the brain, and the third had positive HIV serology (M. Phillips and A. J. Vazquez Control. Clin. Trials 8, 338-342; 1987).

Everyone's perceived roles suddenly changed, and the outcome was devastating. The subjects ceased to be healthy students with bright prospects. They were furious that the research had transformed them into patients under threat of death. The researchers ceased to be physicians in full control of the situation. They were transformed from investigators into counsellors, and that left them confused and defensive.

All the research studies had been approved by an ethical committee.

We suggested two ways to improve future research protocols: participants should be alerted in advance to the possibility that the research in which they are participating might reveal a previously unsuspected illness, and investigators should be required to formulate a plan to cope with this contingency.

Maybe the time has come to act on this modest proposal?

Michael Phillips

Menssana Research, 1 Horizon Road, Suite 1415, Fort Lee, New Jersey 07024-6510, USA

\section{Solid evidence for bubble fusion?}

Sir - Your News story "Bubble-based fusion bursts onto the scene" (Nature 432, 940-941; 2004) states that bubblefusion work "remains in limbo" after research conducted at Oak Ridge National Laboratory (ORNL) yielded inconclusive results in 2002.

However, a second paper was published by researchers at Purdue/ORNL in March last year and provided additional evidence for bubble fusion (R. P. Taleyarkhan et al. Phys. Rev. E69, 036109; 2004). This paper underwent a second thorough review by a different group of ORNL scientists who supported its publication.

In my view, the 2004 paper provides evidence that shifts the question from "Can we drive fusion this way?" to "Can we produce net fusion energy this way?".

A great deal of work will have to be performed before that more difficult question can be answered.

\section{Ross Tessien}

Impulse Devices, 13366 Grass Valley Avenue, Grass Valley, California 95945, USA

\section{India must cooperate on tsunami warning system}

Sir - Following the 26 December tsunami, international survey teams working in the affected areas ("On the trail of destruction" Nature 433, 350-353; 2005) have held educational seminars attended by government ministers, local professionals, emergency management and, on occasion, even students. The emphasis has been on explaining tsunami generation and impact, lessons learned from recent tsunamis, information on the operation of tsunami warning centres and preliminary findings.

Unlike similar meetings in Sri Lanka, the Maldives and Indonesia, the meeting hosted by the Indian National Academy of Sciences in Delhi on 21-22 January was more focused on presenting national capabilities in remote sensing, seismology and storm warnings. The meeting concluded with a list of action items. There was little discussion of arguably the most fundamental aspect of a warning system - the communication of the warning and actions resulting from this. This omission was supposedly justified by India's experience with storm warnings. 
Yet neither this storm-warning experience nor the existence of India's sophisticated seismic networks led to warnings being issued on 26 December, once the tsunami had struck the Andaman and Nicobar Islands. The tsunami did not hit the Indian mainland for another two hours. Allegedly, communications links had survived in Port Blair on the Andaman Islands, not to mention nearby airforce and navy bases that were affected. Some have argued that up to 40,000 people might have been saved if they had been warned. Further, India issued an incorrect warning a few days after the tsunami hit, triggering massive panic in India and Sri Lanka.

At the same meeting, India announced that it could develop new systems and models "based on end-to-end principles" in two years, using the best brains in India. For reference, the United States and Japan took more than 20 years to develop validated numerical models to predict tsunami evolution. And it took the US National Oceanic and Atmospheric Administration 30 years to fully develop its bottom-pressure recorders, which have been reliably detecting tsunamis for the past ten years.

India has an opportunity to establish a regional warning centre for the Indian ocean, thus ending its self-imposed isolation in sharing seismic data. It has the communications infrastructure and the scientific talent to serve its citizens and the international community. But the idea that India can do it alone is misguided.

Costas Synolakis

Department of Civil Engineering,

University of Southern California,

Los Angeles, California 90089-2531, USA

\section{Ethics and ethnoflora}

Sir - Pleased though we were to read the generous and thorough review of our book Ethnoflora of the Soqotra Archipelago in Nature ("Back to the roots" Nature 432, 805-806; 2004), we feel that — given the politically sensitive environment in which we work - we need to address the comment that "many ethical issues ... are not generally considered in this book".

We were scrupulous, for example, about informing all those who contributed to our book about their intellectual property rights. This was in strict compliance with the Convention on Biological Diversity (and with our contract). All informants recorded on tape, in Soqotri, their agreement and their understanding of the purpose of the research.

Regarding the recognition of intellectual contribution, our book includes a list of some 140 Soqotran contributors. (Female informants could not be named individually for cultural reasons.) And although Ethnoflora did not specifically mention any of the educational and capacity-building programmes in the archipelago in which we are involved, these activities are fully reported elsewhere.

Tony Miller*, Miranda Morris $\dagger$

${ }^{\star}$ Royal Botanic Garden, Inverleith Row,

Edinburgh EH3 5LR, UK

$\dagger$ School of History, University of St Andrews,

St Katherine's Lodge, The Scores,

St Andrews, Fife KY16 9AL, UK

\section{Biologists do not pose a threat to deep-sea vents}

Sir - Magnus Johnson suggests, in Correspondence ("Oceans need protection from scientists too" Nature 433, 105; 2005), that "uncoordinated and unregulated" research is one of the greatest threats to hydrothermal vent habitats. We offer information to the contrary. Furthermore, we suggest that the vent-research community is unusually well-organized internationally to examine the effects of researcher activities and to implement a code of conduct.

As with most field studies, it is possible to cite examples of overexuberant sampling, especially in the years following the discovery of vents. But potential effects of sampling were recognized early (V. J. Tunnicliffe Geophys. Res. 95, 12961-12966; 1990) and researchers at vents are proactive in developing mechanisms to reduce sampling effects.

Although it is true that the main effects on hydrothermal vents come from scientists because the only visitors at vents are scientists, today much more emphasis is placed on management and conservation to reduce the collection of organisms. Many known vents are no longer sampled and effort is concentrated at a few sites.

The current ethos of vent marine scientists is evident in the activities of the Biogeography of Chemosynthetic Ecosytems (ChEss) programme (www.soc. soton.ac.uk/chess) within the 'census of marine life' initiative. ChEss helped to convene a fact-finding workshop on hydrothermal ecosystems with the United Nations' International Seabed Authority (ISA) last September. The ISA is responsible for developing the legislation required to ensure and provide for responsible and sustainable activity throughout the world's deep-ocean environments. There is also a draft Code of Conduct pending approval by InterRidge (www.interridge.org), the office that coordinates international studies on mid-ocean ridges.

Canada's Endeavour Hot Vents Marine Protected Area, which Johnson highlights, was established with the strong support of scientists. Examine the website that Johnson cites to see that there are 'zones' of activities — including 'No Sample' areas. Johnson's comment that a senior scientist advised him not to complain is a sad one. Any discipline needs to keep its ears open to possible abuse as well as ensuring responsible reporting of the facts.

We have worked as scientists on many aspects of deep-sea oceanography for nearly 30 years and share all concerns about damage to that environment. The lessons we have learned at hydrothermal vents are ones that we now apply at other chemosynthetically driven ecosystems, such as cold seeps and whale falls.

Paul Tyler, Christopher German,

Verena Tunnicliffe

Southampton Oceanography Centre, University of Southampton, Southampton SO14 3ZH, UK

Signed on behalf of 18 international members of the ChEss

programme steering group

\section{Making sure corrections don't vanish online}

Sir - We have counted the numbers of errata, corrigenda, corrections and addenda published in all 2004 Nature print issues, across all sections of the journal. During the past year, Nature has reported flaws in 32 peer-reviewed research papers, of which 24 were corrigenda (author corrections) and 8 were errata (journal corrections); there were also 2 addenda. Although all these corrections were published last year, 14 of the erroneous papers were published before 2004 . Within the other sections of the journal there were 14 errors reported.

Worryingly, in 14 out of 34 cases Nature failed to attach an amendment page with the online PDF of the original paper. Nature has also failed to provide an amendment notice with the abstract or HTML version of several research papers (7 times out of 34). Similar problems arise for corrections to non-research items such as News stories.

With the widespread practice of accessing, printing and circulating PDF files through the Internet, it seems advisable to take this matter seriously. Eun-Hee Shim ${ }^{\star}$, Vishwas Parekh $\dagger$

${ }^{*}$ Department of Biochemistry,

$\dagger$ Department of Hematology-Oncology,

St Jude Children's Research Hospital,

Memphis, Tennessee 38105, USA

Corrections published in Nature should be linked online to the article being corrected, both in the text of the correction and in the HTML of the original article. The articles identified by Shim and Parekh have now been linked in this way. Editor, Nature 